LAWRENCE LIVERMORE NATIONAL LABORATORY

\title{
Thermal Decomposition Kinetics of HMX
}

Alan K. Burnham and Randall K. Weese

May 20, 2004 
This document was prepared as an account of work sponsored by an agency of the United States Government. Neither the United States Government nor the University of California nor any of their employees, makes any warranty, express or implied, or assumes any legal liability or responsibility for the accuracy, completeness, or usefulness of any information, apparatus, product, or process disclosed, or represents that its use would not infringe privately owned rights. Reference herein to any specific commercial product, process, or service by trade name, trademark, manufacturer, or otherwise, does not necessarily constitute or imply its endorsement, recommendation, or favoring by the United States Government or the University of California. The views and opinions of authors expressed herein do not necessarily state or reflect those of the United States Government or the University of California, and shall not be used for advertising or product endorsement purposes. 


\title{
Thermal Decomposition Kinetics of HMX
}

\author{
Alan K. Burnham and Randall K. Weese \\ Lawrence Livermore National Laboratory \\ P. O. Box 808 \\ Livermore, CA 94551-0808
}

\begin{abstract}
Nucleation-growth kinetic expressions are derived for thermal decomposition of HMX from a variety of types of data, including mass loss for isothermal and constant rate heating in an open pan, and heat flow for isothermal and constant rate heating in open and closed pans. Conditions are identified in which thermal runaway is small to nonexistent, which typically means temperatures less than $255^{\circ} \mathrm{C}$ and heating rates less than $1{ }^{\circ} \mathrm{C} / \mathrm{min}$. Activation energies are typically in the 140 to $150 \mathrm{~kJ} / \mathrm{mol}$ regime for open pan experiments and about $160 \mathrm{~kJ} / \mathrm{mol}$ for sealed pan experiments. Our activation energies are about 10\% lower than those derived from data supplied by the University of Utah, which we consider the best previous work. The reaction clearly displays more than one process, and most likely three processes, which are most clearly evident in open pan experiments. The reaction is accelerated for closed pan experiments, and one global reaction appears to fit the data well.
\end{abstract}

Keywords: thermal decomposition, chemical kinetics, activation energy, HMX, thermal analysis

\section{Introduction}

Optimizing the application of high explosives for innumerable applications often employs mechanistic models of the detonation process. Such models usually require an estimation of the amount of gas generated and heat released as a function of time and temperature. Methods for calibrating the gas and heat generation rates range from fitting empirical equations to complex, integrated experiments to detailed mechanistic chemical kinetic models.

Thermal analysis, specifically thermogravimetric analysis (TGA), differential thermal analysis (DTA), and differential scanning calorimetry (DSC) is frequently used as a part of developing global kinetic models of the decomposition process.

Unfortunately, the range of experimental results and kinetic parameters from these techniques is so great that some modelers regard such kinetic information with great skepticism, and justifiably so.

The objective of this paper is to obtain meaningful global kinetic models for mass loss and heat generation for the decomposition of HMX. We conclude that the best prior work in this regard is that of Wight and Vyazovkin, ${ }^{1}$ who took great effort to maintain conditions where thermal runaway of the sample is avoided. We agree with their conclusion that the experiments must be done at relatively low temperatures or heating rates, that the mean activation energy for HMX decomposition is in the vicinity of 150 $\mathrm{kJ} / \mathrm{mol}$, and that it varies with extent of conversion. We also present a comparison to 
unpublished University of Utah data, collected by Peter Lofy and provided by Prof. Chuck Wight. Activation energies from our data tend to be about 10\% lower than from the Utah data, but that is a small difference compared to the spread of values in the literature.

Ancillary conclusions of Wight and Vyazovkin are that the best way to derive kinetic parameters is with "model free" isoconversional methods and that model fitting gives unreliable results. We agree with their conclusion in that regard for the subset of data analysis procedures they considered, which are typical for the thermal analysis community. However, we show that model fitting can be a useful approach to analyzing the data when multiple thermal histories are analyzed simultaneously. Comparing behavior for isothermal and linear heating can also give insight into model validity.

In addition, we show that the kinetic parameters for heat release and mass loss are not the same, because they measure different processes, and that the heat release kinetics depend on the nature of the sample confinement, which influences the extent of secondary reactions involving gaseous products.

\section{Experimental Methods}

\subsection{Samples}

The $\beta$-HMX used in this study (batch B-844) was manufactured by Holston Defense Corporation for Lawrence Livermore National Laboratory using the Bachmann synthesis process. It was determined to be $>99.90 \%$ pure as analyzed by HPLC for RDX. Particle size analysis indicated that $>90 \%$ of the material was between 30 and $500 \mu \mathrm{m}$ in diameter.

\subsection{Reaction Measurements}

Simultaneous TGA and DTA measurements were carried out using a TA Instruments Simultaneous Differential Thermogravimetric Analyzer (SDT), model 2960, manufactured by TA Instruments. Degradation was carried out under nitrogen carrier gas at a flow rate of $100 \mathrm{~cm}^{3} / \mathrm{min}$. A Differential Scanning Calorimeter (DSC), TA Instrument Model 2920, and its associated software, Universal Analysis, were used for additional analyses. All samples were weighed in a Sartorius MC 5 Electronic balance accurate to $\leq 5 \mu \mathrm{g}$. All sample pan total weights were matched with a reference pan of the same mass (or within $100 \mu \mathrm{g}$ ) to match heat flow due to the heat capacity of aluminum for the sample and reference.

For kinetics measurements, sample weights of $0.5 \mathrm{mg}$ or less were decomposed from $\sim 20{ }^{\circ} \mathrm{C}$ to $350{ }^{\circ} \mathrm{C}$ at heating rates ranging from 0.1 to $1.0^{\circ} \mathrm{C} / \mathrm{min}$ or isothermally at or between 230 and $250^{\circ} \mathrm{C}$. Figure 1 demonstrates why it is necessary to use such small samples and slow heating rates. Here, a 2-mg sample was heated at $10{ }^{\circ} \mathrm{C} / \mathrm{min}$. During decomposition, the measured sample temperature deviated by more than $10^{\circ} \mathrm{C}$ from linearity. When plotted versus temperature, both the temperature difference and the mass showed reversals as the sample cooled from the main stage of decomposition. The maximum temperature excursion was still about $5{ }^{\circ} \mathrm{C}$ at $2.5{ }^{\circ} \mathrm{C} / \mathrm{min}$ but decreased to less than $0.5{ }^{\circ} \mathrm{C}$ at $1{ }^{\circ} \mathrm{C} / \mathrm{min}$. Decreasing the sample size to less than $0.5 \mathrm{mg}$ ensured that the temperature error was negligible and that the decomposition occurred from the solid state. 
Another problem at high heating rates is that the melting endotherm at $280-285{ }^{\circ} \mathrm{C}$ distorts both the thermal history and the heat flow data as the peak decomposition temperature passes through that regime as heating rate increases from 2.7 to $7.4{ }^{\circ} \mathrm{C} / \mathrm{min}$, as shown in Figure 2. The decomposition rate is possibly affected by phase change. In addition, the total amount of heat generated increases as heating rate increases due to increased gas-phase reactions. Both of these factors support the need to stay below 1 ${ }^{\circ} \mathrm{C} / \mathrm{min}$ to determine valid kinetic parameters.

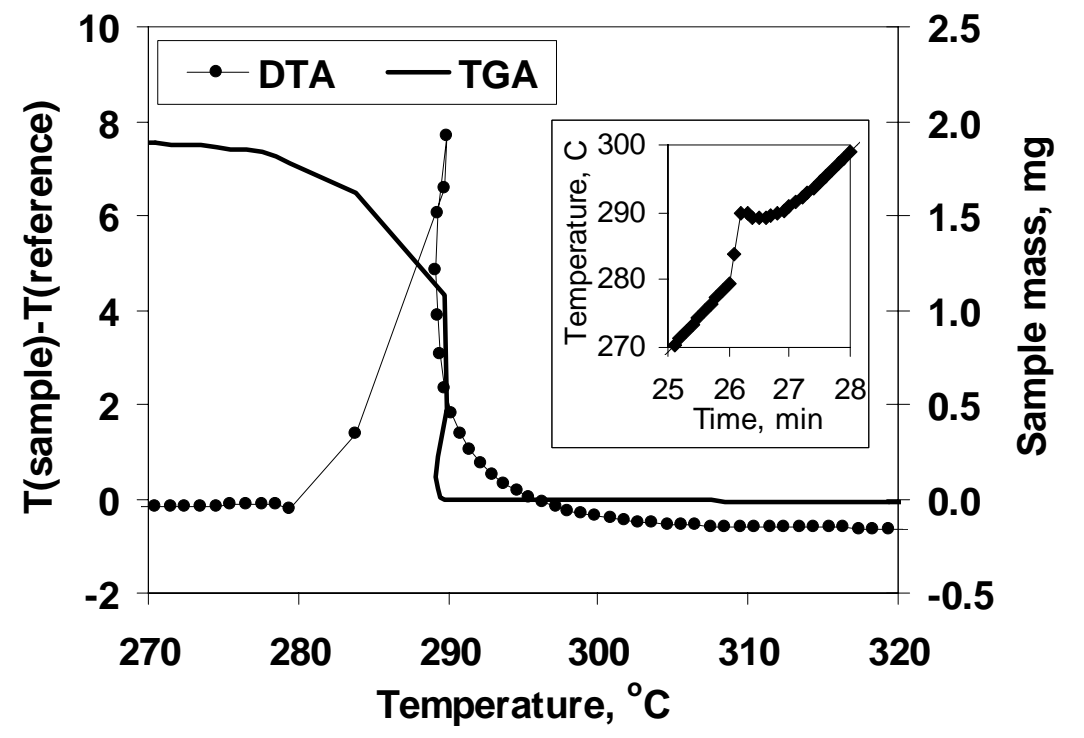

Figure 1. Heat flow and remaining mass for a relatively large sample (2 $\mathrm{mg}$ ) and rapid heating rate $\left(10^{\circ} \mathrm{C} / \mathrm{min}\right)$ showing thermal runaway due to the exothermal reaction. Our kinetics experiments used heating rates less than $1{ }^{\circ} \mathrm{C} / \mathrm{min}$ and samples less than $0.5 \mathrm{mg}$.

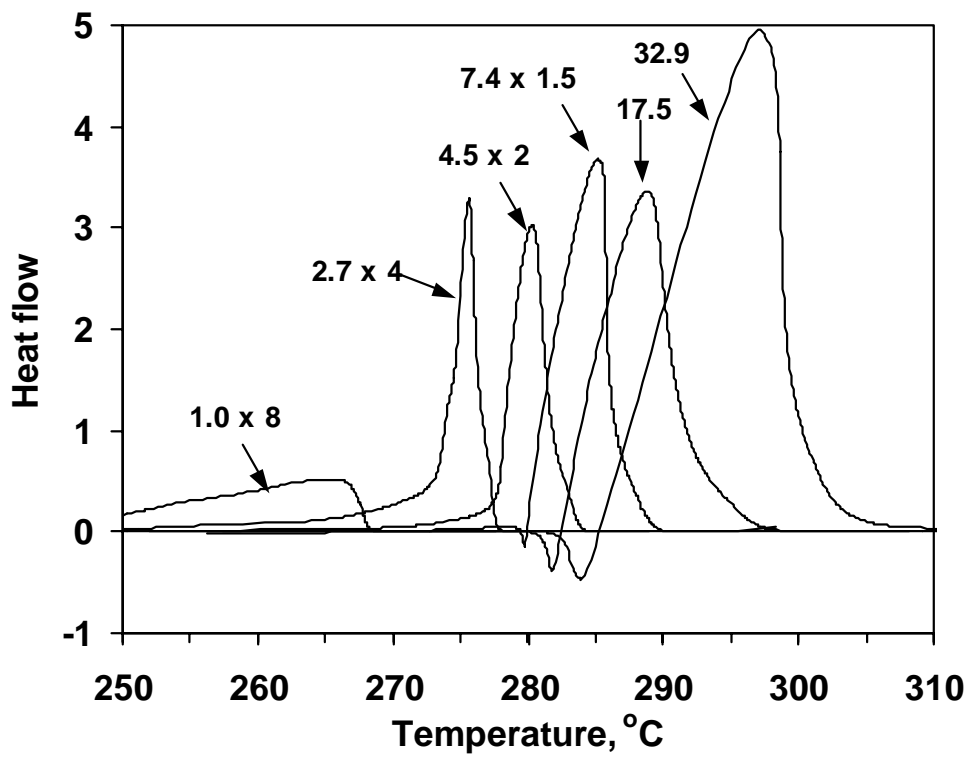

Figure 2. Heat flow rate divided by total heat flow for HMX heated in a perforated DSC pan at heating rates from 1.0 to $32.9^{\circ} \mathrm{C} / \mathrm{min}$. The multiplying numbers are the scale changes to make the runs more equal in height for visibility. The endotherms between 280 and $285^{\circ} \mathrm{C}$ are due to melting. 


\section{Kinetic Analysis}

Data were collected and processed so that each experiment had between 100 and 1500 points covering the region over which any reaction occurred. Kinetic analysis was done with the LLNL program Kinetics05, which is an upgrade of a program described earlier [2]. Three principal methods of kinetic analysis were used.

The first is Friedman's method [3]. For an nth-order Arrhenius reaction,

$$
\ln (-\mathrm{d}(1-\alpha) / \mathrm{dt})=-\mathrm{E} / \mathrm{RT}+\ln \left(\mathrm{A}(1-\alpha)^{\mathrm{n}}\right)
$$

where $\alpha$ is the fraction converted and $n$ is the reaction order. A plot of $\ln (-d(1-\alpha) / d t)$ at a given fraction reacted versus the $1 / \mathrm{T}$ value at which that conversion is reached for several different thermal histories will be linear with a slope equal to $-\mathrm{E} / \mathrm{R}$ and an intercept of $\ln \left(\mathrm{A}(1-\alpha)^{\mathrm{n}}\right)$.

The second is an extension [2,4] of Kissinger's method [5], where a plot of a function of heating rate and $\mathrm{T}_{\max }$ versus $1 / \mathrm{T}_{\max }$ gives $\mathrm{E} / \mathrm{R}$ from the slope and $\mathrm{A} / \mathrm{E}$ from the intercept:

$$
\ln \left(\mathrm{H}_{\mathrm{r}} / \mathrm{RT}_{\max }^{2}\right)=-\mathrm{E} / \mathrm{RT}_{\max }+\ln (\mathrm{A} / \mathrm{E})
$$

Our extension looks at the ratio of the measured and calculated profile widths and the profile asymmetry to estimate other reaction parameters such as reaction order and nucleation characteristics.

The third is nonlinear regression to an extended Prout-Tompkins (PT) model [4]:

$$
\mathrm{d}(1-\alpha) / \mathrm{dt}=-\mathrm{k}(1-\alpha)^{\mathrm{n}}(1-\mathrm{q}(1-\alpha))^{\mathrm{m}}
$$

where $\mathrm{m}$ is a nucleation parameter, $\mathrm{q}$ is an initiation parameter ordinarily fixed at 0.99, and $\mathrm{k}=\operatorname{Aexp}(-\mathrm{E} / \mathrm{RT})$. The nonlinear regression minimized the squared residuals simultaneously for a chosen criterion. Ordinarily, we weighted each experiment equally and minimized the residuals for both the reaction extent and reaction rate.

\section{Results}

\subsection{Single reaction fits to mass loss}

Mass loss provides a measure of both evaporation and formation of volatile products. Table 1 summarizes the rate constants derived for mass loss from an open pan for both constant heating rate and isothermal conditions. Isoconversional kinetics are determined for the two sets separately and agree qualitatively. The modified Kissinger analysis gives a similar activation and frequency factor and initial estimates for reaction order and nucleation order. Nonlinear regression of both sets separately and together give similar results.

The only definitive way to compare various kinetic expressions is to plot the data and calculations together. In Figure 3, the reactions rates for the isothermal and constant heating rates experiments are compared to their respective fits. The single reaction 
models fit reasonably well, but there are clear indications of multiple reaction processes. In Figure 4, the fractions reacted for both sets of data are compared with all three sets of nonlinear regression kinetic parameters. The three sets of parameters agree well with each other and the data at the highest temperature and heating rate. The isothermal kinetic parameters become progressively slower than the other two as temperature decreases. This is reflected in the higher activation energy from the isothermal experiments.

Table 1. Kinetic parameters derived from mass loss for both constant heating rate and isothermal heating of HMX at LLNL.

\begin{tabular}{|c|c|c|c|c|c|r|}
\hline & \multicolumn{2}{|c|}{ Constant heating rate } & \multicolumn{3}{c|}{ Isothermal } \\
\hline Friedman & $\mathrm{A}_{\mathrm{n}=1}$ & $\mathrm{E}$ & $\sigma_{\mathrm{E}}$ & $\mathrm{A}_{\mathrm{n}=1}$ & $\mathrm{E}$ & $\sigma_{\mathrm{E}}$ \\
\hline 0.1 & $9.13 \mathrm{E}+08$ & 125.5 & 6.3 & $1.53 \mathrm{E}+11$ & 148.8 & 6.9 \\
\hline 0.2 & $1.80 \mathrm{E}+11$ & 146.1 & 0.5 & $1.44 \mathrm{E}+11$ & 145.2 & 29.0 \\
\hline 0.3 & $1.91 \mathrm{E}+11$ & 145.5 & 2.0 & $1.27 \mathrm{E}+09$ & 123.8 & 23.8 \\
\hline 0.4 & $7.29 \mathrm{E}+10$ & 140.6 & 0.8 & $3.20 \mathrm{E}+10$ & 137.0 & 16.2 \\
\hline 0.5 & $6.39 \mathrm{E}+10$ & 139.2 & 1.6 & $2.27 \mathrm{E}+12$ & 154.6 & 11.2 \\
\hline 0.6 & $9.70 \mathrm{E}+10$ & 140.0 & 3.1 & $1.91 \mathrm{E}+12$ & 153.4 & 10.0 \\
\hline 0.7 & $2.75 \mathrm{E}+11$ & 143.7 & 2.9 & $3.26 \mathrm{E}+12$ & 155.3 & 21.9 \\
\hline 0.8 & $9.07 \mathrm{E}+11$ & 147.7 & 2.2 & $6.97 \mathrm{E}+12$ & 157.6 & 5.9 \\
\hline 0.9 & $5.20 \mathrm{E}+12$ & 153.2 & 2.6 & $3.64 \mathrm{E}+13$ & 162.9 & 2.7 \\
\hline & & & & & & \\
\hline Kissinger & $\mathrm{A}_{\mathrm{n}=1}$ & $\mathrm{E}$ & $\sigma_{\mathrm{E}}$ & $\mathrm{A}_{\mathrm{PT}}$ & $\mathrm{n}$ & $\mathrm{m}$ \\
\hline (c.h.r. only) & $1.30 \mathrm{E}+10$ & 135.6 & 3.5 & $3.54 \mathrm{E} 10$ & 0.649 & 0.722 \\
\hline & & & & & & \\
\hline Nonlin. Reg. PT & $\mathrm{A}_{\mathrm{PT}}$ & $\mathrm{E}$ & $\mathrm{n}$ & $\mathrm{m}$ & $\mathrm{T}_{50 \%}{ }^{*}$ & \\
\hline const. h. r. & $1.087 \mathrm{E}+11$ & 141.4 & 0.483 & 0.539 & 249.9 & \\
\hline isothermal & $9.243 \mathrm{E}+11$ & 148.9 & 0.901 & 0.740 & 252.0 & \\
\hline both & $5.501 \mathrm{E}+10$ & 137.7 & 0.639 & 0.647 & 250.9 & \\
\hline
\end{tabular}

*Calculated temperature for $50 \%$ conversion at $0.5{ }^{\circ} \mathrm{C} / \mathrm{min}$ 

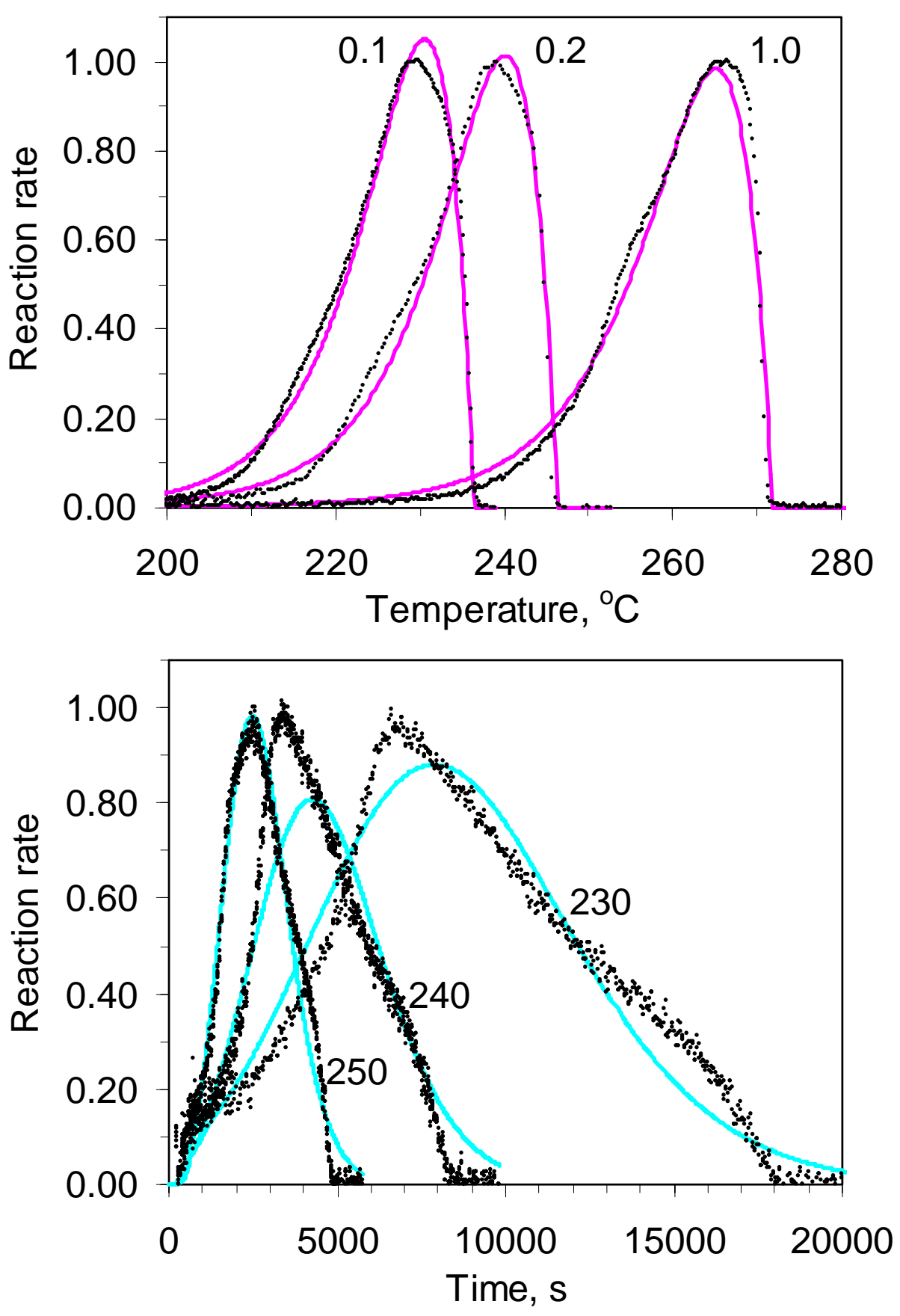

Figure 3. Comparison of the isothermal and constant-heating-rate reaction rates with their respective fits to an extended Prout-Tompkins model. The nonlinear regression analysis simultaneously minimized the squared residuals for both rates and fractions reacted for all experiments of each type. 

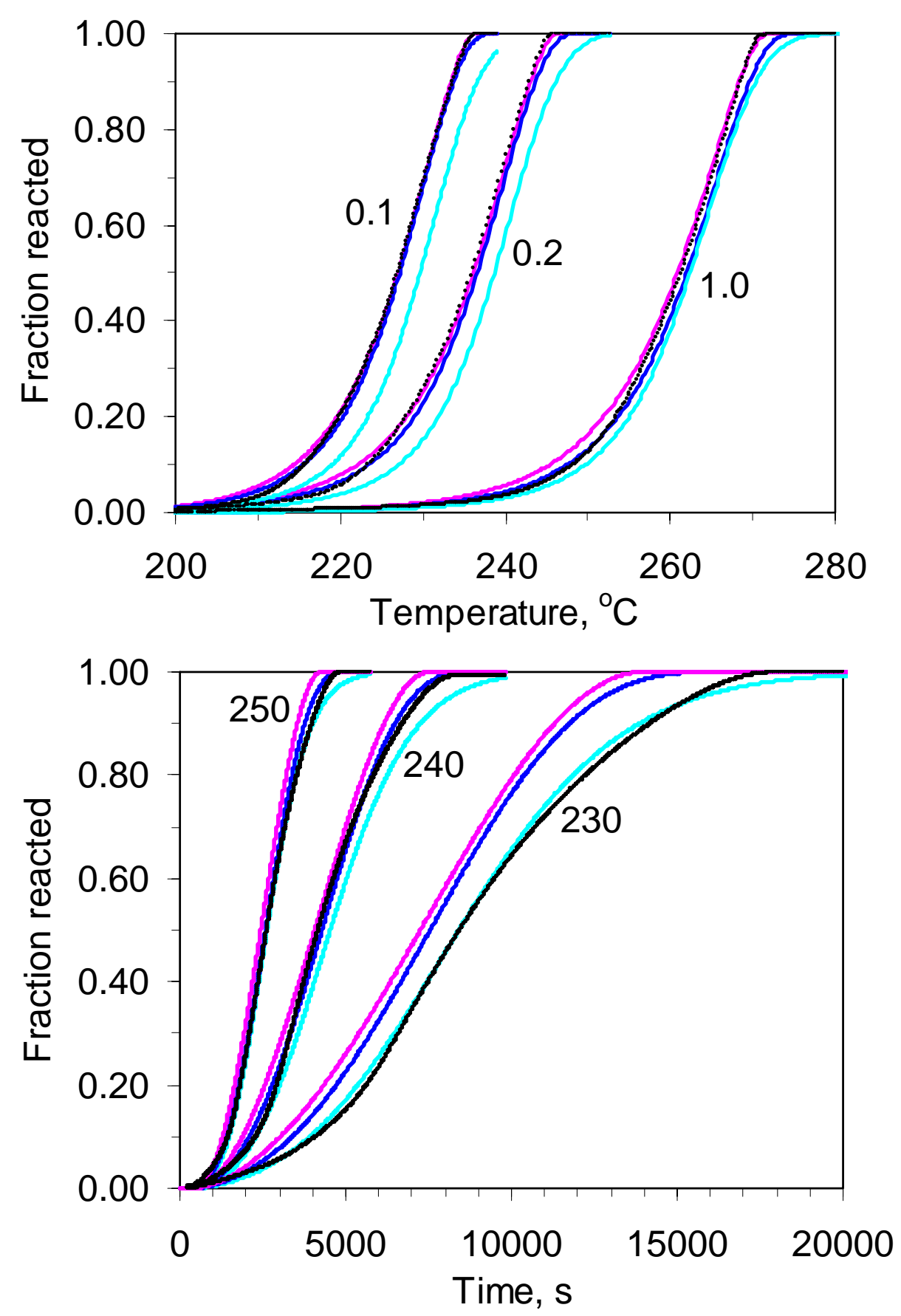

Figure 4. Comparison of all three models to fractions reacted at constant heating rates (top) and constant temperatures (bottom). The red curve is the fit to that the constant heating rate data, the turquoise curve is a fit to the isothermal data, and the blue curve is a fit to both data sets simultaneously. 
The results from LLNL can be compared to parameters derived from data supplied by Prof. Chuck Wight at the University of Utah. This data was collected by one of his students, Peter Lofy. Our analysis is given in Table 2. A comparison of isoconversional activation energies provided by Wight to the LLNL Friedman analysis in Figure 5, and a comparison of measured and calculated fractions reacted are given in Figure 6. The calculated temperature for $50 \%$ conversion at a heating rate of $0.5{ }^{\circ} \mathrm{C} / \mathrm{min}$ is within a few degrees of that in Table 1.

Table 2. Kinetic parameters derived from mass loss for both constant heating rate and isothermal heating of HMX at the University of Utah.

\begin{tabular}{|l|c|c|c|c|c|r|}
\hline & \multicolumn{2}{|c|}{ Constant heating rate } & \multicolumn{3}{c|}{ Isothermal } \\
\hline Friedman & $\mathrm{A}_{\mathrm{n}=1}$ & \multicolumn{1}{c|}{$\mathrm{E}$} & \multicolumn{1}{c|}{$\sigma_{\mathrm{E}}$} & $\mathrm{A}_{\mathrm{n}=1}$ & \multicolumn{1}{c|}{$\mathrm{E}$} & $\sigma_{\mathrm{E}}$ \\
\hline 0.1 & $5.00 \mathrm{E}+10$ & 143.1 & 25.6 & $1.41 \mathrm{E}+07$ & 108.3 & 45.2 \\
\hline 0.2 & $1.51 \mathrm{E}+14$ & 175.8 & 14.5 & $2.53 \mathrm{E}+11$ & 147.5 & 26.7 \\
\hline 0.3 & $3.66 \mathrm{E}+13$ & 167.5 & 19.6 & $4.20 \mathrm{E}+13$ & 168.0 & 32.7 \\
\hline 0.4 & $3.55 \mathrm{E}+09$ & 126.5 & 10.0 & $4.28 \mathrm{E}+14$ & 176.9 & 16.3 \\
\hline 0.5 & $7.18 \mathrm{E}+07$ & 108.7 & 6.3 & $1.43 \mathrm{E}+12$ & 151.7 & 14.7 \\
\hline 0.6 & $2.55 \mathrm{E}+08$ & 113.3 & 5.9 & $2.69 \mathrm{E}+12$ & 153.4 & 5.4 \\
\hline 0.7 & $7.26 \mathrm{E}+09$ & 126.9 & 7.4 & $3.06 \mathrm{E}+14$ & 173.4 & 26.0 \\
\hline 0.8 & $1.94 \mathrm{E}+11$ & 140.2 & 9.7 & $8.85 \mathrm{E}+13$ & 166.9 & 8.6 \\
\hline 0.9 & $8.52 \mathrm{E}+11$ & 144.8 & 7.5 & $7.49 \mathrm{E}+13$ & 164.2 & 44.5 \\
\hline & & & & & & \\
\hline Kissinger & $\mathrm{A}_{\mathrm{n}=1}$ & $\mathrm{E}$ & $\sigma_{\mathrm{E}}$ & $\mathrm{A}_{\mathrm{PT}}$ & $\mathrm{n}$ & $\mathrm{m}$ \\
\hline (const. h.r. only) & $1.347 \mathrm{E}+09$ & 125.1 & 7.2 & $5.135 \mathrm{E} 09$ & 0.900 & 0.865 \\
\hline & & & & & & \\
\hline Nonlin. Reg. PT & $\mathrm{A}_{\mathrm{PT}}$ & $\mathrm{E}$ & $\mathrm{n}$ & $\mathrm{m}$ & $\mathrm{q}$ & $\mathrm{T}_{50 \%}{ }^{*}$ \\
\hline const. h. r. & $1.495 \mathrm{E}+11$ & 140.0 & 0.700 & 1.068 & 0.90 & 247.6 \\
\hline isothermal & $6.427 \mathrm{E}+13$ & 166.6 & 0.700 & 0.982 & 0.90 & 249.1 \\
\hline both & $1.654 \mathrm{E}+12$ & 151.7 & 0.700 & 0.837 & 0.90 & 248.3 \\
\hline
\end{tabular}

${ }^{*}$ Calculated temperature for $50 \%$ conversion at $0.5{ }^{\circ} \mathrm{C} / \mathrm{min}$

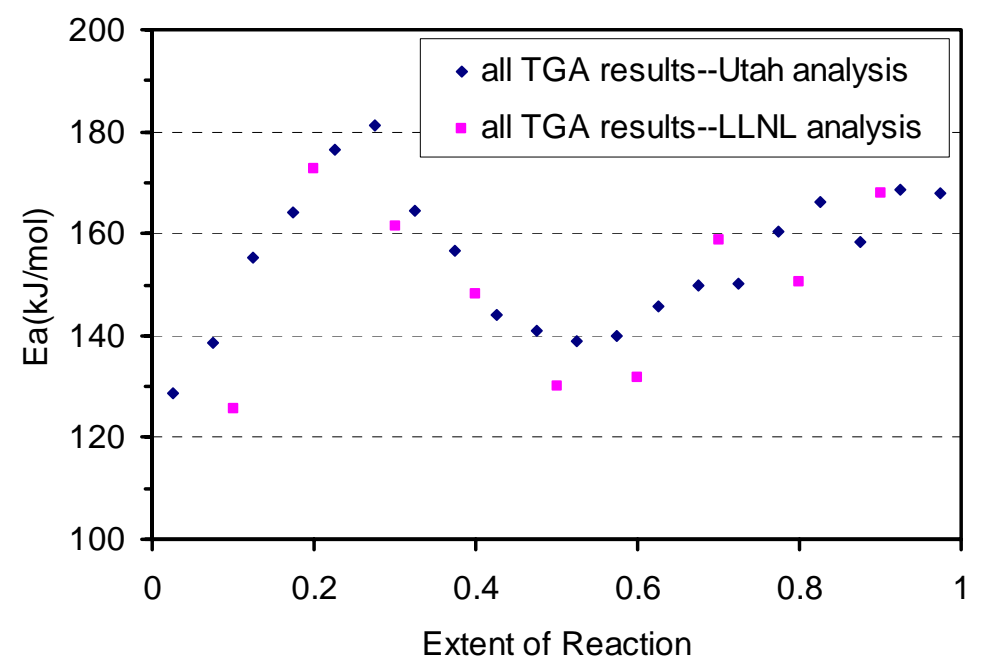

Figure 5. Comparison of isoconversional activation energies by the Utah and LLNL analysis methods. The agreement is very good. 

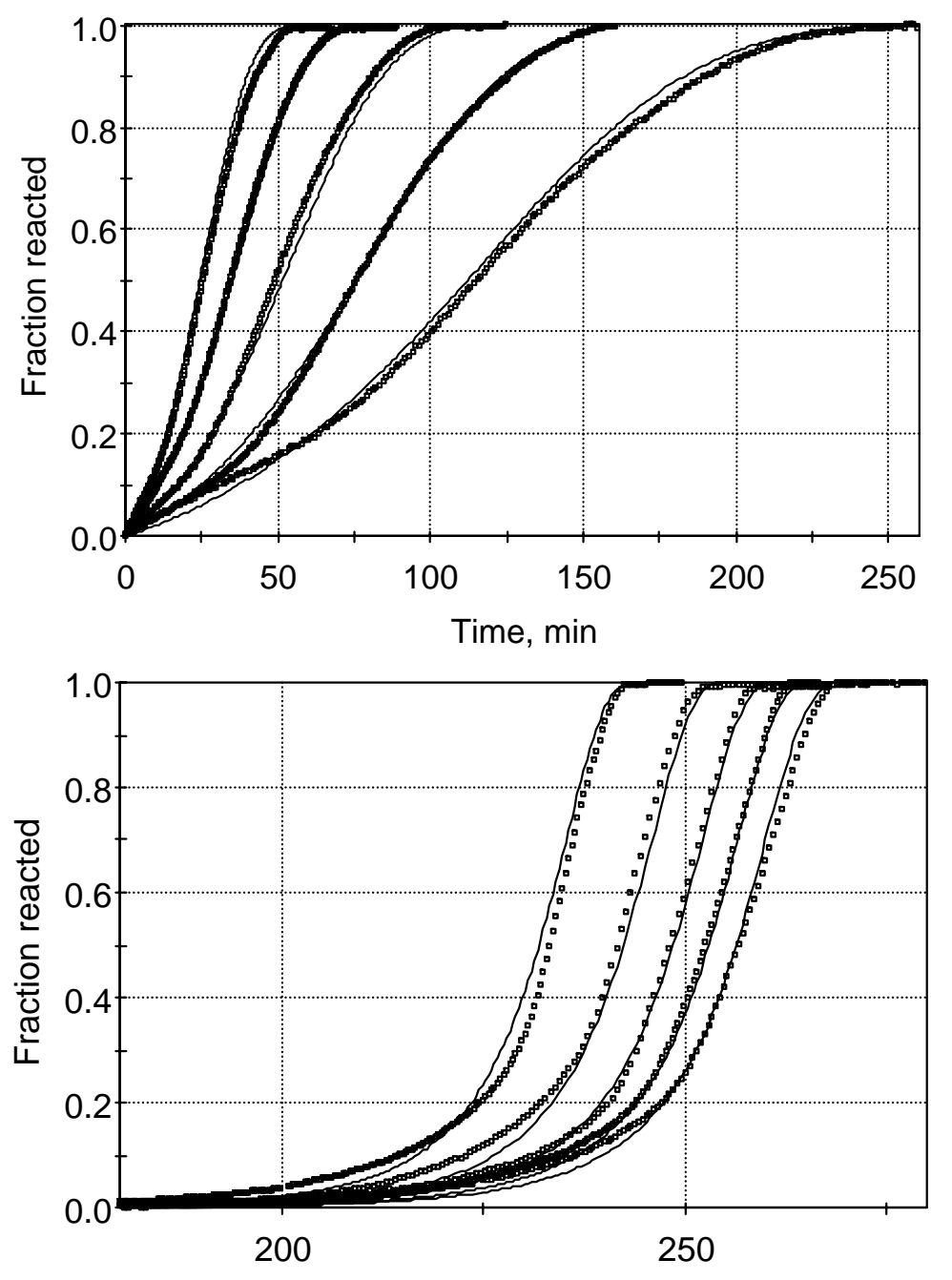

Temperature, C

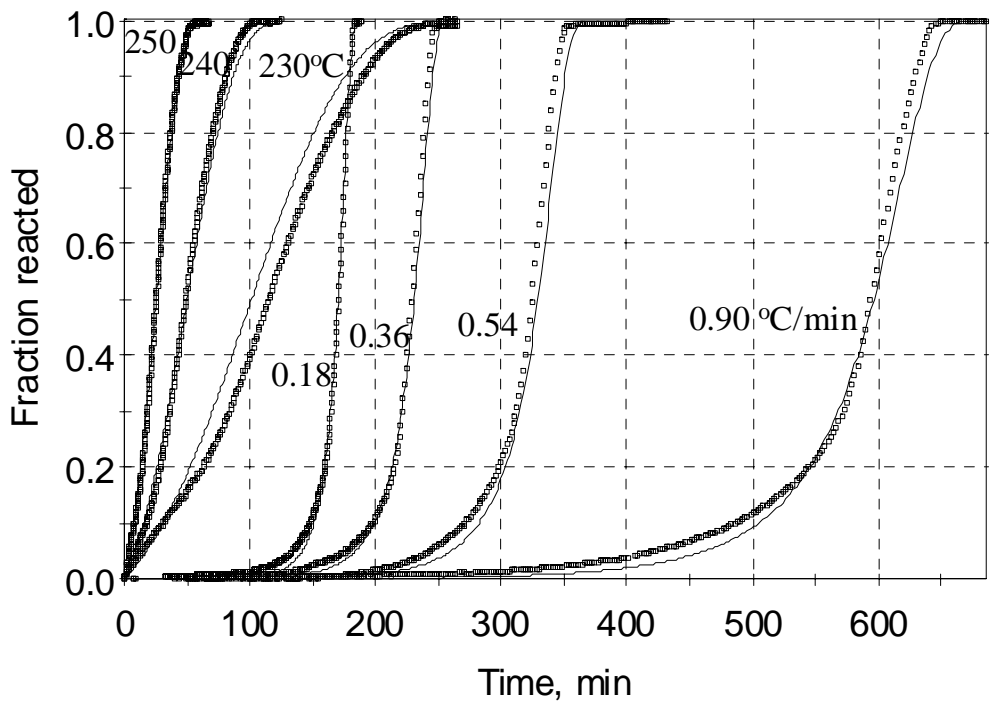

Figure 6. Measured fractions reacted and nonlinear regression fits to an extended PT model for isothermal $\left(230-250^{\circ} \mathrm{C}\right)$, constant heating rate $\left(0.18-0.9^{\circ} \mathrm{C} / \mathrm{min}\right)$, and both sets simultaneously for HMX mass loss data from the University of Utah. 


\subsection{Kinetics of heat release from DTA at a constant heating rate}

Heat release does not necessarily follow the same kinetics as mass loss, in that they represent different weighted sums of complex processes. The SDT apparatus provides a way of directly comparing how close the two processes are. Of course, the full heat of detonation is not realized in an open-pan decomposition, nor is it possible to accurately measure the heat generated in an open-pan DTA experiment. Consequently, for making this comparison, we have normalized the DTA results to match the initial reaction rate curves.

The resulting comparison of mass loss and heat release at three heating rates is shown in Figure 7. The multiple reaction processes noticed in the previous section for mass loss are clearer in the heat release profiles. The low-temperature shoulder is close to the tallest peak at $1{ }^{\circ} \mathrm{C} / \mathrm{min}$. A high-temperature shoulder is also pronounced at 0.2 and $1{ }^{\circ} \mathrm{C} / \mathrm{min}$. At $2.5^{\circ} \mathrm{C} / \mathrm{min}$, the reaction profiles change qualitatively, as was noted in Figure 2. This probably corresponds to thermal runaway or gas-phase ignition.
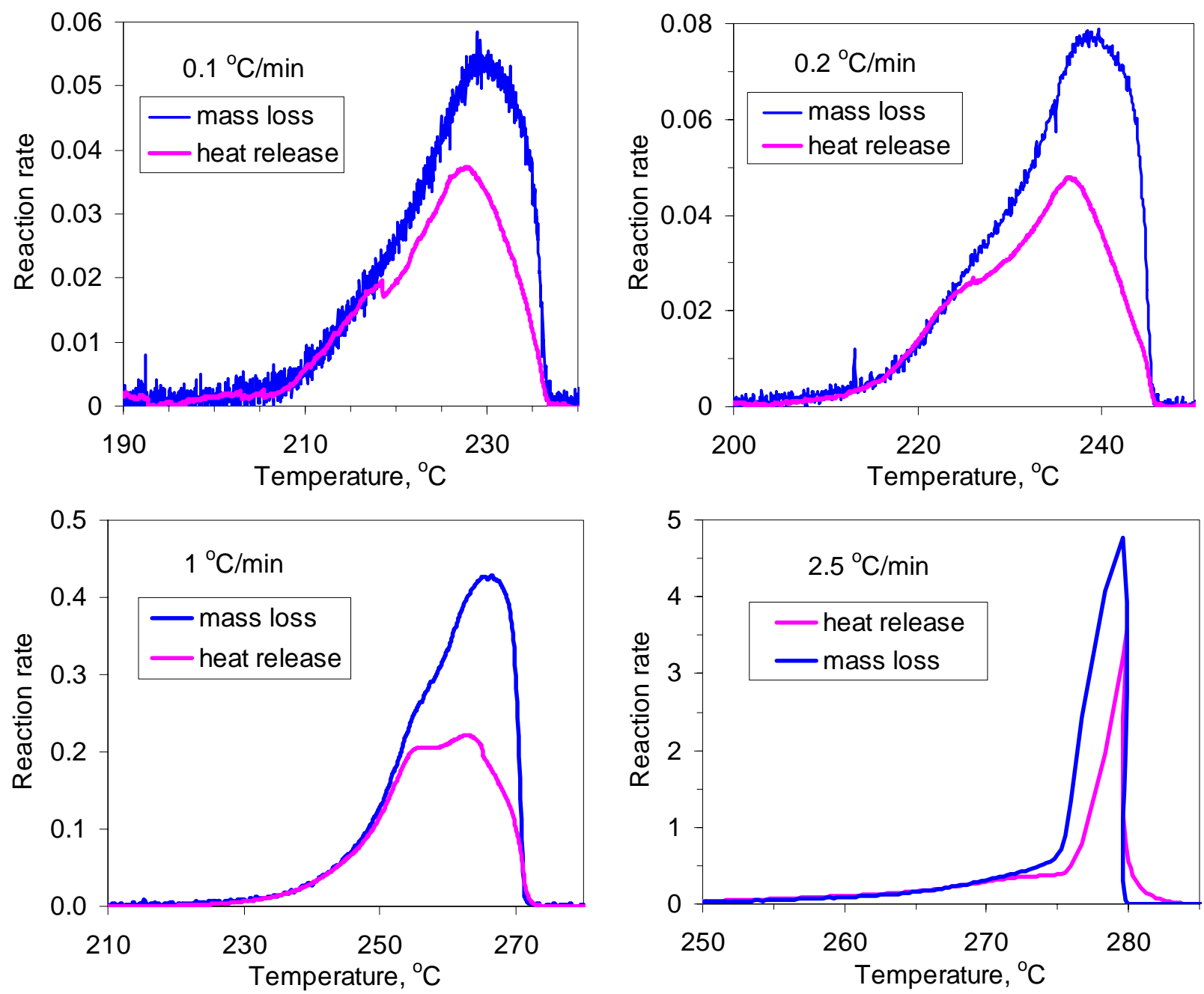

Figure 7. Comparison of heat release and mass loss reaction rates for HMX at four heating rates. 
The DTA data was fitted to the various kinetic models as before. Table 3 reports both Friedman and Modified Coats-Redfern isoconversional analysis. The modified Coats-Redern method is base on the integral rather than the rate as for the Friedman method. Figure 8 shows a comparison of measured and calculated reaction curves for single and three-reaction nucleation growth models. Although the three-reaction model provides a qualitative improvement in agreement with some aspects of the data, the overall residual sum of squares are about equal. This lack of improvement is probably due to two factors. First, the single reaction model is truly optimized by the computer program, which the three-reaction model is partially optimized by iteration. Also, the profile shape changes with heating rate, indicating the reaction mechanism is not three independent parallel reactions. Consequently, the low temperature shoulder is overestimated at the low heating rate and underestimated at the high heating rate.

Table 3. Kinetic parameters from HMX DTA data at constant heating rates of $0.1,0.2$, and $1.0^{\circ} \mathrm{C} / \mathrm{min}$.

\begin{tabular}{|c|c|c|c|c|c|r|}
\hline & \multicolumn{3}{|c|}{ Friedman } & \multicolumn{3}{c|}{ Modified Coats-Redfern } \\
\hline Fraction reacted & $\mathrm{A}_{\mathrm{n}=1}$ & $\mathrm{E}$ & $\sigma_{\mathrm{E}}$ & $\mathrm{A}_{\mathrm{n}=1}$ & $\mathrm{E}$ & $\sigma_{\mathrm{E}}$ \\
\hline 0.1 & $1.29 \mathrm{E}+09$ & 125.8 & 9.1 & $7.92 \mathrm{E}+09$ & 137.4 & 7.9 \\
\hline 0.2 & $1.45 \mathrm{E}+10$ & 134.5 & 6.7 & $6.78 \mathrm{E}+09$ & 134.9 & 7.5 \\
\hline 0.3 & $1.96 \mathrm{E}+12$ & 154.6 & 5.7 & $1.48 \mathrm{E}+10$ & 137.1 & 7.5 \\
\hline 0.4 & $6.43 \mathrm{E}+11$ & 149.3 & 1.6 & $3.29 \mathrm{E}+10$ & 139.6 & 6.8 \\
\hline 0.5 & $6.54 \mathrm{E}+10$ & 139.0 & 2.0 & $4.69 \mathrm{E}+10$ & 140.5 & 5.7 \\
\hline 0.6 & $1.35 \mathrm{E}+10$ & 131.4 & 2.4 & $4.69 \mathrm{E}+10$ & 139.9 & 4.9 \\
\hline 0.7 & $1.73 \mathrm{E}+10$ & 131.5 & 3.7 & $4.23 \mathrm{E}+10$ & 138.8 & 4.6 \\
\hline 0.8 & $3.44 \mathrm{E}+10$ & 133.7 & 3.5 & $4.33 \mathrm{E}+10$ & 138.2 & 4.4 \\
\hline 0.9 & $9.41 \mathrm{E}+10$ & 136.9 & 1.5 & $5.00 \mathrm{E}+10$ & 138.0 & 4.1 \\
\hline & & & & & & \\
\hline Single PT rxn. & $\mathrm{A}_{\mathrm{PT}}$ & $\mathrm{E}$ & $\mathrm{n}$ & $\mathrm{m}$ & & $\mathrm{T}_{50 \%}{ }^{*}$ \\
\hline & $5.957 \mathrm{E}+10$ & 138.0 & 0.651 & 0.523 & & 246.9 \\
\hline & & & & & & \\
\hline Three PT rxns. & $\mathrm{A}_{\mathrm{PT}}$ & $\mathrm{E}$ & $\mathrm{n}$ & $\mathrm{m}$ & $\mathrm{f}$ & 242.4 \\
\hline & $2.500 \mathrm{E}+10$ & 127.6 & 1.00 & 1.00 & 0.29 & \\
\hline & $9.600 \mathrm{E}+10$ & 136.0 & 1.00 & 0.90 & 0.49 & \\
\hline & $6.300 \mathrm{E}+10$ & 136.0 & 1.00 & 0.50 & 0.22 & \\
\hline
\end{tabular}

${ }^{*}$ Calculated temperature for $50 \%$ conversion at $0.5{ }^{\circ} \mathrm{C} / \mathrm{min}$ 

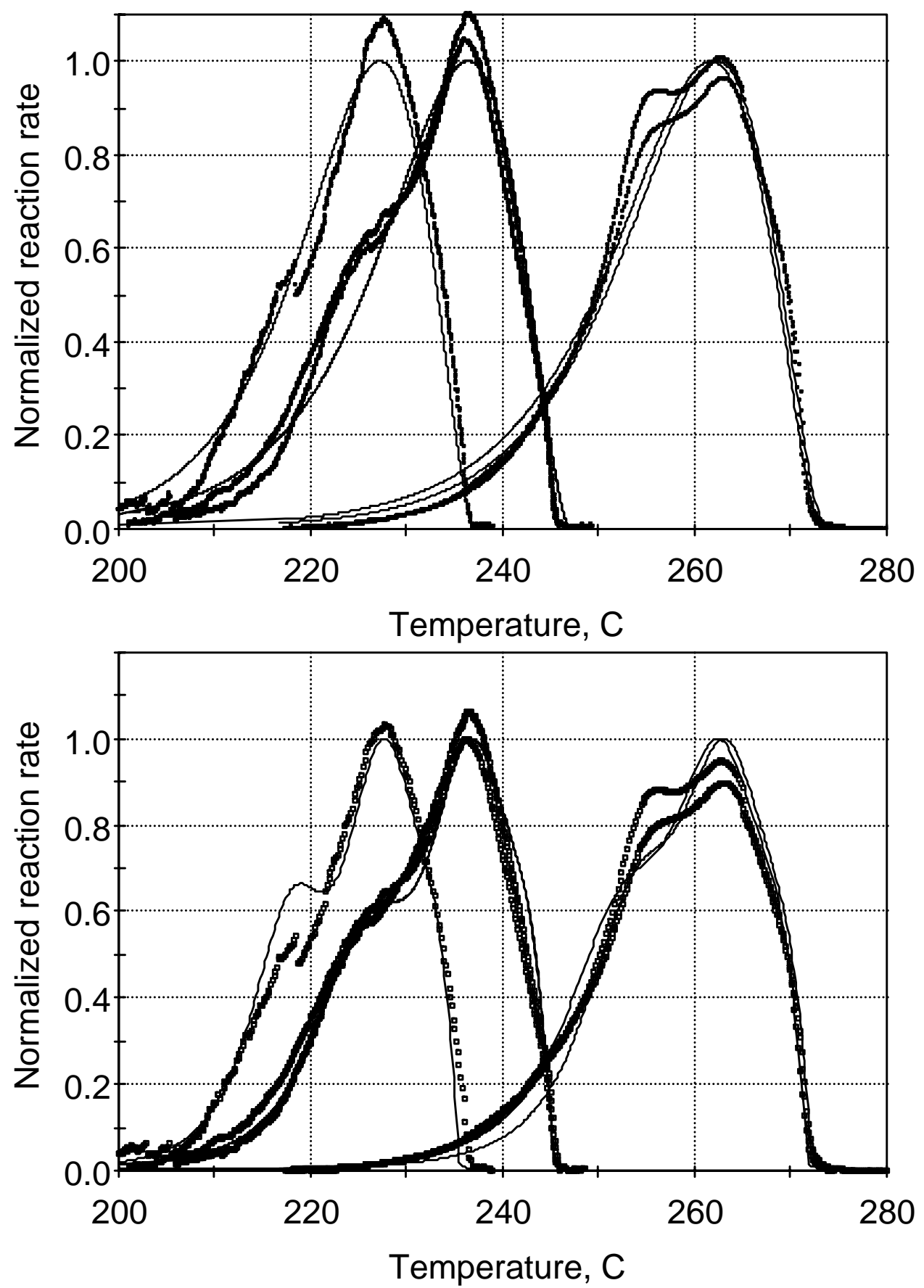

Figure 8. Comparison of LLNL DTA data at $0.1,0.2$, and $1.0{ }^{\circ} \mathrm{C} / \mathrm{min}$ with the one- and three-reaction models in Table 3. The residual sum of squares is not improved substantially, because the relative abundance of the three reactions does not appear to be independent of heating rate, so the profile shape changes. 


\subsection{Kinetics of heat release from isothermal DSC}

Differential scanning calorimetry gives more reliable baselines that DTA for estimating reaction rates. Even so, the thermal transients at the beginning of a nominally isothermal experiment do provide a challenge. Our experiments were conducted in the modulated mode, with a peak-to-valley amplitude of $10{ }^{\circ} \mathrm{C}$ and cycle frequency ranging from $1.6 / \mathrm{min}$ at $232{ }^{\circ} \mathrm{C}$ to $0.6 / \mathrm{min}$ at $251{ }^{\circ} \mathrm{C}$. Fourier filtering is used to separate the reactive (irreversible) and heat capacity (reversible) components of the heat flow. The filtered irreversible signal, a nonlinear estimation of the baseline, and the net HMX decomposition rate are given in Figure 9. The reaction rate again shows multiple reaction processes, with the final process abruptly dropping to the baseline.

The kinetic parameters derived from this data are given in Table 3. The isoconversional activation energies are more variable and somewhat higher than from other experiments. A comparison of the fit with the data is given in Figure 10. The model fits the profile overall, but it misses a few key aspects. First, the asymptotic approach to baseline is not consistent with the abrupt drop in the experiments. The drop is not as pronounced at $232{ }^{\circ} \mathrm{C}$, but that may be a baseline correction limitation. Second, the fit tends to miss the sharpness of the initial rise in reaction rate and peaks at longer times for the two higher temperatures.

Figure 11 compares the isothermal DSC data with calculations using the kinetics derived from the constant-heating-rate DTA data. The calculations agree with experiment pretty well at the higher two temperatures, although it misses the change in relative height of the first two peaks from 241 to $251^{\circ} \mathrm{C}$. However, they are too fast at the lowest temperature. The slowness of the isothermal reaction rate at $230{ }^{\circ} \mathrm{C}$ appears to be a recurring theme.

Table 3. Kinetic parameters from HMX isothermal DSC data at 232, 241, and $251{ }^{\circ} \mathrm{C}$.

\begin{tabular}{|c|c|r|r|c|}
\hline & \multicolumn{4}{|c|}{ Friedman } \\
\hline Fraction reacted & $\mathrm{A}_{\mathrm{n}=1}$ & \multicolumn{1}{|c|}{$\mathrm{E}$} & \multicolumn{1}{|c|}{$\sigma_{\mathrm{E}}$} & \\
\hline 0.1 & $2.54 \mathrm{E}+15$ & 187.2 & 43.9 & \\
\hline 0.2 & $6.79 \mathrm{E}+09$ & 130.4 & 22.0 & \\
\hline 0.3 & $4.74 \mathrm{E}+09$ & 128.2 & 8.1 & \\
\hline 0.4 & $3.13 \mathrm{E}+12$ & 155.5 & 1.9 & \\
\hline 0.5 & $1.25 \mathrm{E}+15$ & 180.4 & 4.1 & \\
\hline 0.6 & $1.06 \mathrm{E}+16$ & 189.0 & 13.4 & \\
\hline 0.7 & $4.46 \mathrm{E}+16$ & 194.7 & 21.6 & \\
\hline 0.8 & $1.13 \mathrm{E}+18$ & 208.1 & 29.0 & \\
\hline 0.9 & $1.00 \mathrm{E}+19$ & 216.6 & 17.4 & \\
\hline & & & & \\
\hline Single PT rxn.* & $\mathrm{A}_{\mathrm{PT}}$ & $\mathrm{E}$ & $\mathrm{n}$ & $\mathrm{m}$ \\
\hline & $2.324 \mathrm{E}+12$ & 150.3 & 1.195 & 0.850 \\
\hline
\end{tabular}

*Calculated temperature for $50 \%$ conversion at $0.5^{\circ} \mathrm{C} / \mathrm{min}$ equals $247.9^{\circ} \mathrm{C}$ 

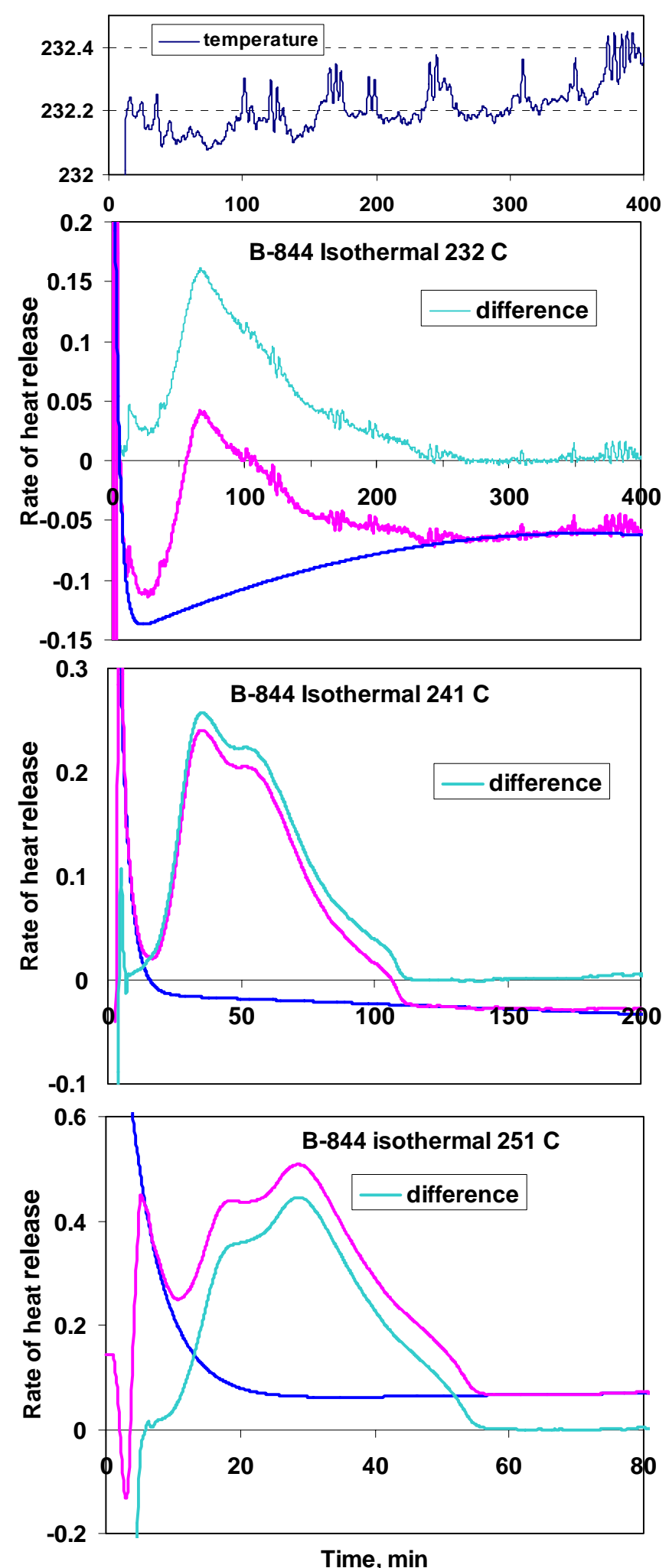

Figure 9. Baseline corrections of isothermal modulated DSC data. The upper figure shows residual spikes in the lowest temperature after Fourier transform, which are also reflected in the rate data. 


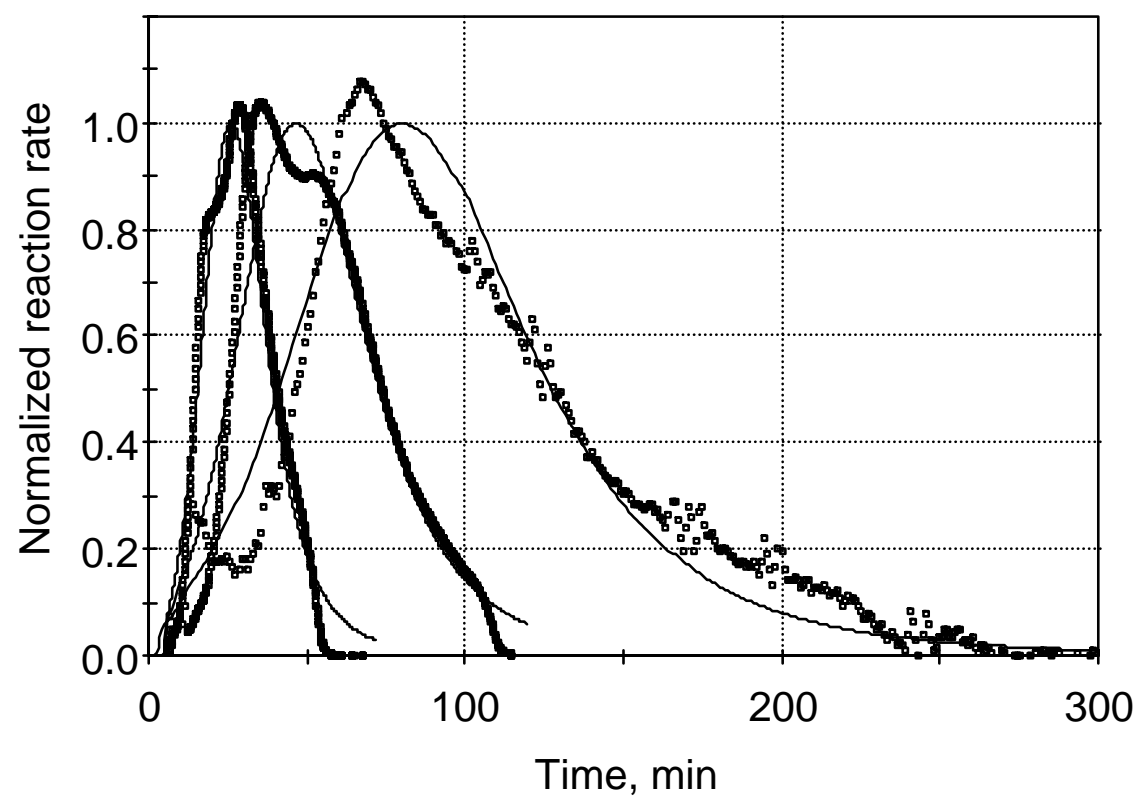

Figure 10. Fit of isothermal open-pan DSC data at 232, 241, and $251{ }^{\circ} \mathrm{C}$ to a nucleationgrowth kinetic model.

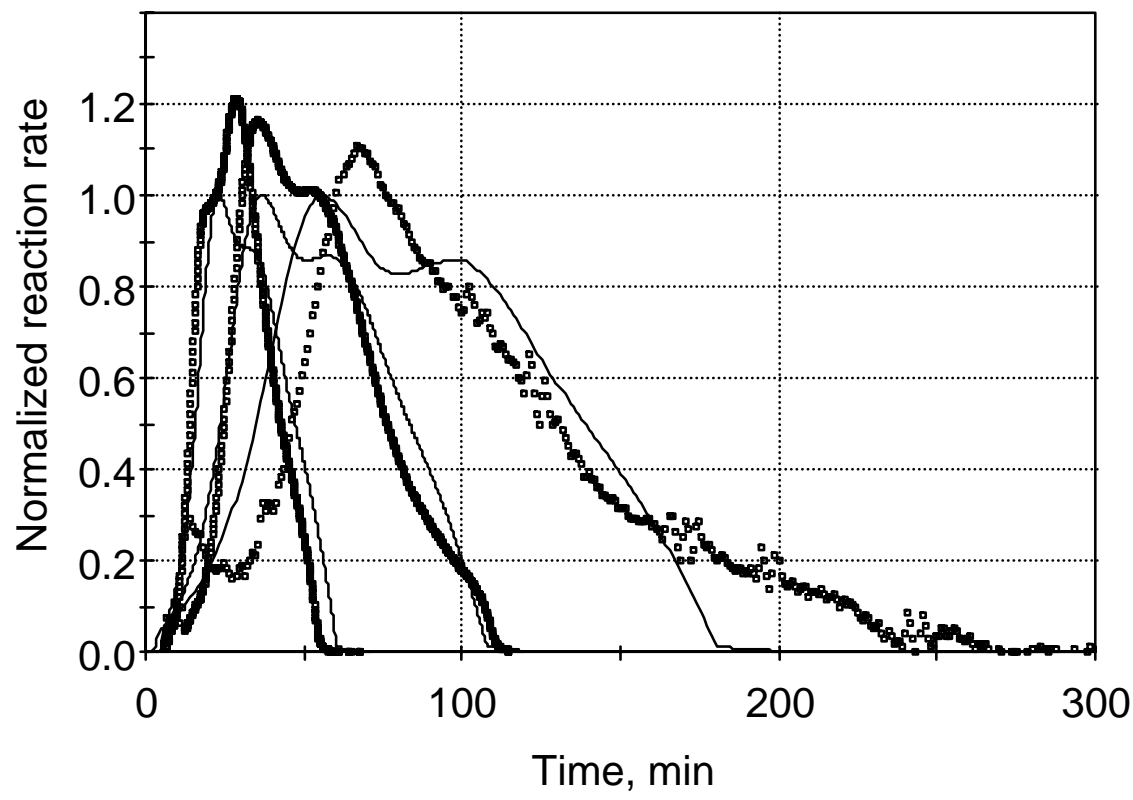

Figure 11. Comparison of the isothermal DSC data with the three-reaction model derived from the DTA data at a constant heating rate. 


\subsection{Comparison to heat release from University of Utah data}

We next compare our results to those from analyzing constant heating rate and isothermal data from the University of Utah. The results are summarized in Table 4, and a comparison of measurements and calculations is shown in Figure 12. Not as much time was spent optimizing these parameters, but they are shown for completeness. The activation energies are similar, but generally higher than we obtained. The reaction profiles show some of the same multi-reaction characteristics. Again, the lowest isothermal reaction rate is slower than expected from fitting both data types simultaneously. Note that the two lowest temperature experiments in Figure 12 (top) appear somewhat incompatible. It is also noteworthy that for a constant heating rate, the heat release kinetics are about $10{ }^{\circ} \mathrm{C}$ slower (higher temperature) than the mass loss kinetics.

Table 4. Heat release kinetic parameters derived from both constant heating rate and isothermal heating of HMX at the University of Utah. A reaction order of 1.0 was assumed in all cases.

\begin{tabular}{|c|c|c|c|}
\hline & \multicolumn{3}{|c|}{ Isothermal and const. h.r. } \\
\hline Friedman & $\mathrm{A}_{\mathrm{n}=1}$ & $\mathrm{E}$ & $\sigma_{\mathrm{E}}$ \\
\hline 0.1 & $2.98 \mathrm{E}+13$ & 171.0 & 37.9 \\
\hline 0.2 & $8.32 \mathrm{E}+11$ & 154.0 & 37.2 \\
\hline 0.3 & $6.34 \mathrm{E}+11$ & 151.9 & 33.3 \\
\hline 0.4 & $1.53 \mathrm{E}+12$ & 155.0 & 30.3 \\
\hline 0.5 & $1.45 \mathrm{E}+12$ & 154.2 & 30.3 \\
\hline 0.6 & $5.25 \mathrm{E}+11$ & 149.3 & 35.0 \\
\hline 0.7 & $1.15 \mathrm{E}+11$ & 142.1 & 39.8 \\
\hline 0.8 & $2.54 \mathrm{E}+10$ & 134.8 & 38.2 \\
\hline 0.9 & $3.76 \mathrm{E}+10$ & 135.3 & 29.0 \\
\hline Nonlin. Reg. PT & $\mathrm{A}_{\mathrm{PT}}$ & $\mathrm{E}$ & $\mathrm{m}$ \\
\hline const. h. r. & $3.315 \mathrm{E}+14$ & 177.0 & 0.699 \\
\hline isothermal & $8.387 \mathrm{E}+12$ & 158.1 & 0.911 \\
\hline Both $(q=0.90)$ & $2.184 \mathrm{E}+13$ & 162.7 & 0.869 \\
\hline
\end{tabular}

${ }^{*}$ Calculated temperature for $50 \%$ conversion at $0.5{ }^{\circ} \mathrm{C} / \mathrm{min}$ 

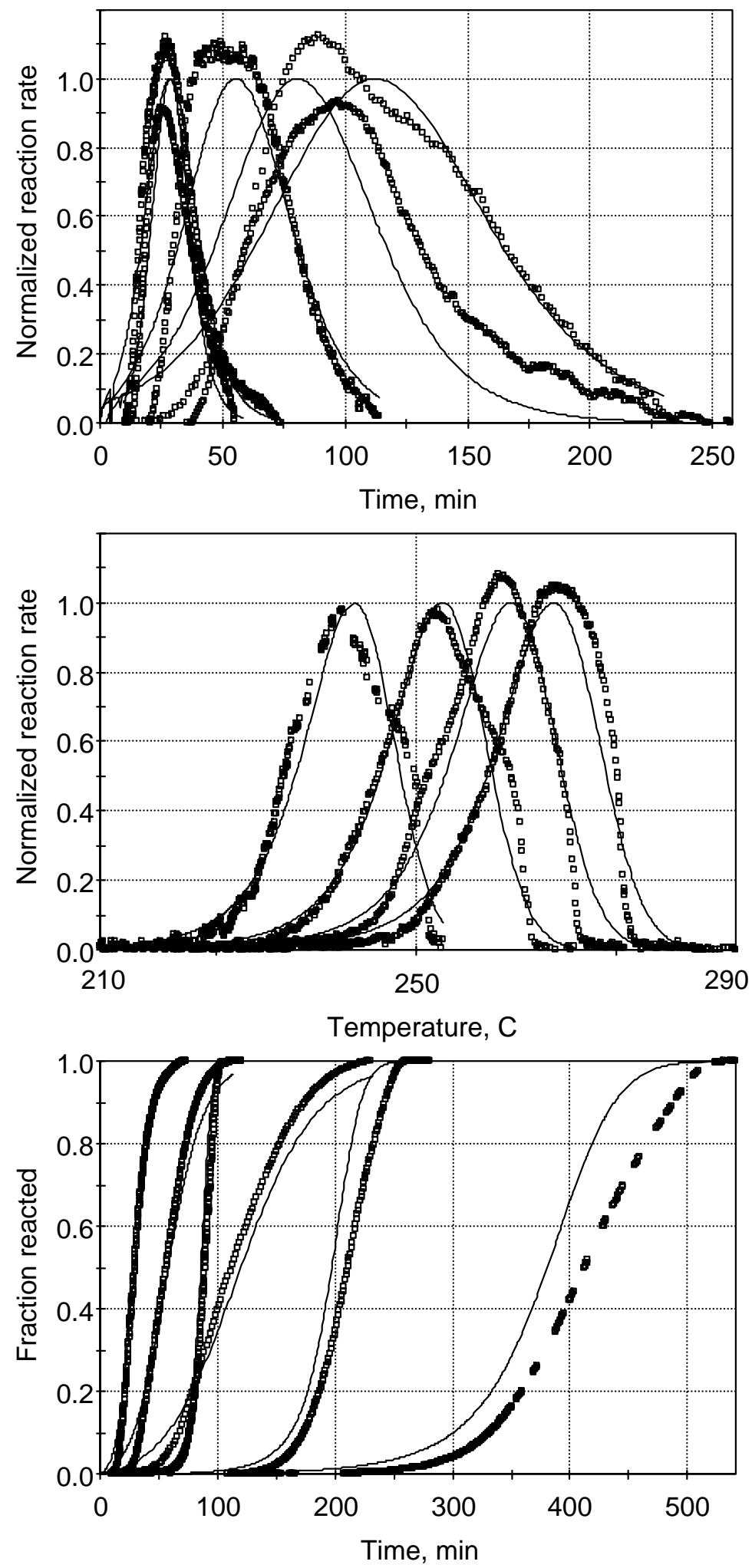

Figure 12. Summary of nucleation-growth model fits to data from University of Utah. Top: isothermal at 235, 242, 247, 257, and $263{ }^{\circ} \mathrm{C}$. Middle: constant heating rates of 0.1 , $0.25,0.5$, and $0.75 \mathrm{C} / \mathrm{min}$. Bottom: simultaneous fit to 235,245 and $255^{\circ} \mathrm{C}$ and 0.1 , 0.25 , and $0.75{ }^{\circ} \mathrm{C} / \mathrm{min}$. 


\subsection{Kinetics of heat release from closed pan experiments}

While the open-pan experiments are interesting and useful to learn about decomposition reaction characteristics, applications of high explosives involve confined spaces in which reaction products can undergo secondary reactions with one another. Furthermore, it is well known that the amount of heat release in an open pan is substantially smaller than in a closed or partially closed pan. Consequently, we undertook a study of heat release kinetics in a hermetically sealed pan. The original intent was to fit the different in open and closed pan experiments to a secondary reaction model, but the secondary reactions actually cause the entire reaction to complete faster, so they are not additive. Comparing to the results in Figure 7, the reaction is completed about $5{ }^{\circ} \mathrm{C}$ sooner at $0.1{ }^{\circ} \mathrm{C} / \mathrm{min}$ and $10^{\circ} \mathrm{C}$ sooner at $1{ }^{\circ} \mathrm{C} / \mathrm{min}$. Consequently, we fitted the closed pan experiments to a single reaction model. The results are summarized in Table 5, and a comparison of measured and calculated rates and fractions reacted are given in Figure 14.

The activation energies from these experiments are the highest from any LLNL data set in this report, but they are still within the range of that determined from the Utah data. The highest heating rate data appears to be sharper and shifted to lower temperatures more than the lowest heating rate data, so one concern is that the highest heating rate may be approaching thermal runaway. That would shift the activation energy above its correct value, with a compensating increase in the frequency factor.

Table 5. Kinetic parameters derived from constant heating rate of HMX in a hermetically sealed vessel at LLNL.

\begin{tabular}{|c|c|c|c|c|c|c|}
\hline & \multicolumn{3}{|c|}{ Constant heating rate } & & & \\
\hline Friedman & $A_{n=1}$ & $\mathrm{E}$ & $\sigma_{\mathrm{E}}$ & & & \\
\hline 0.1 & $1.30 \mathrm{E}+10$ & 136.4 & 0.5 & & & \\
\hline 0.2 & $1.53 \mathrm{E}+12$ & 154.8 & 11.7 & & & \\
\hline 0.3 & $4.68 \mathrm{E}+13$ & 167.9 & 12.9 & & & \\
\hline 0.4 & $1.56 \mathrm{E}+14$ & 171.7 & 6.8 & & & \\
\hline 0.5 & $5.40 \mathrm{E}+14$ & 175.8 & 3.4 & & & \\
\hline 0.6 & $1.37 \mathrm{E}+15$ & 178.4 & 12.0 & & & \\
\hline 0.7 & $5.56 \mathrm{E}+15$ & 182.8 & 19.1 & & & \\
\hline 0.8 & $8.44 \mathrm{E}+16$ & 192.7 & 19.9 & & & \\
\hline 0.9 & $1.42 \mathrm{E}+19$ & 212.3 & 20.6 & & & \\
\hline Kissinger & $A_{n=1}$ & $\mathrm{E}$ & $\sigma_{\mathrm{E}}$ & $\mathrm{A}_{\mathrm{PT}}$ & $\mathrm{n}$ & $\mathrm{m}$ \\
\hline (c.h.r. only) & $2.06 \mathrm{E}+12$ & 156.1 & 31.7 & $8.678 \mathrm{E}+12$ & 0.402 & 0.900 \\
\hline Nonlin. Reg. PT & $\mathrm{A}_{\mathrm{PT}}$ & $\mathrm{E}$ & $\mathrm{n}$ & $\mathrm{m}$ & $\mathrm{T}_{50 \%}{ }^{*}$ & \\
\hline const. h. r. & $1.927 \mathrm{E}+13$ & 162.1 & 0.196 & 0.586 & 246.5 & \\
\hline
\end{tabular}

${ }^{*}$ Calculated temperature for $50 \%$ conversion at $0.5{ }^{\circ} \mathrm{C} / \mathrm{min}$ 

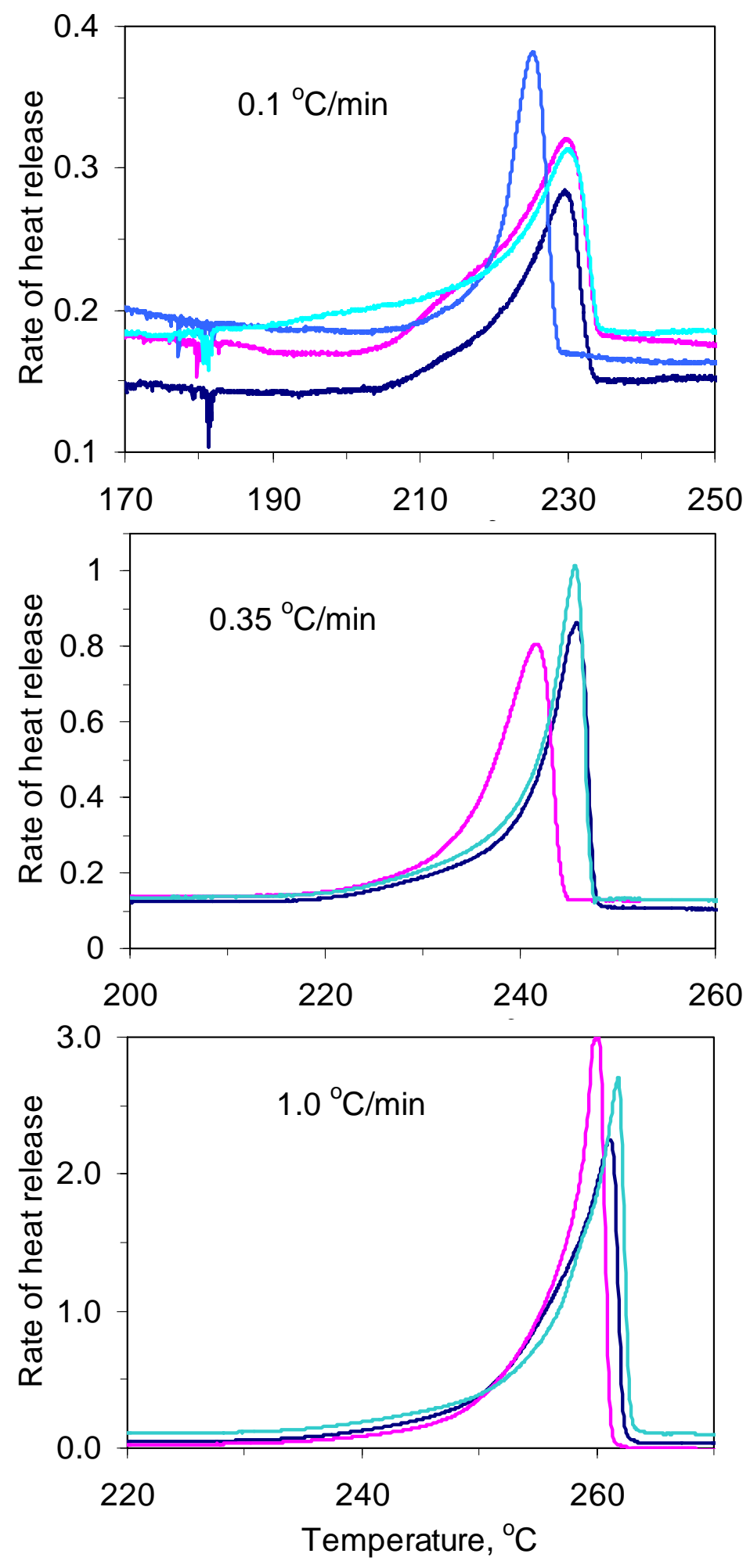

Figure 13. Replicate measurements of heat release for HMX heated at constant rates in a hermetically sealed vessel. The dark blue experiment in each case was selected for kinetic fitting. 

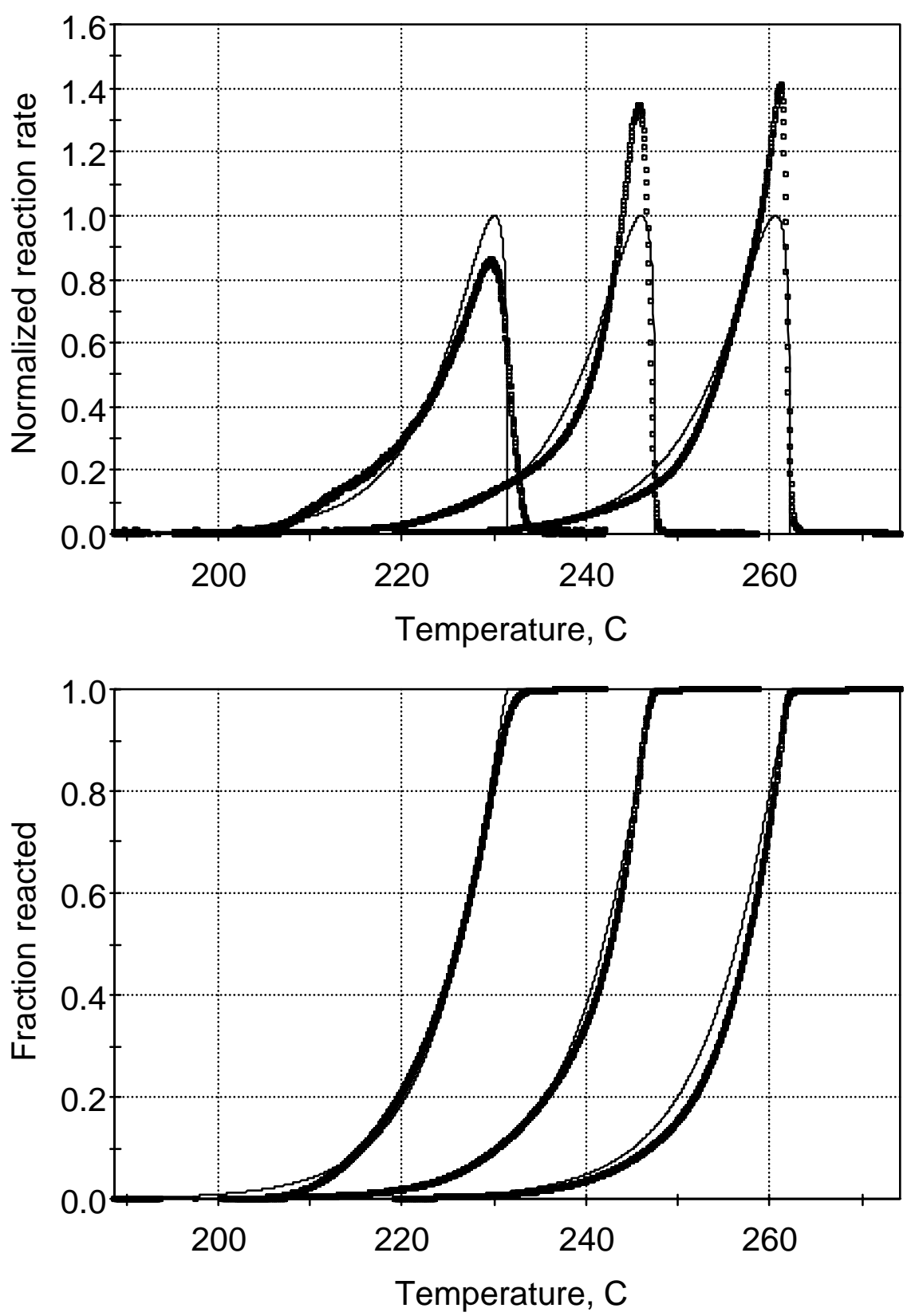

Figure 14. Comparison heat release from heat release from HMX at 0.1, 0.35, and 1.0 ${ }^{\circ} \mathrm{C} / \mathrm{min}$ in a sealed pan with a fit to a single nucleation-growth model: rate (top) and fraction reacted (bottom). 


\section{Conclusions}

A broad range of experiments and kinetic analysis methods, both at LLNL and at the University of Utah, indicates that the global activation energy is in the vicinity of 150 $\mathrm{kJ} / \mathrm{mol}$, which is lower than determined by most workers. In fact, the activation energies for LLNL data are about $10 \%$ lower than from the Utah data. The lower activation energies result from more careful attention to using conditions in which sample selfheating is minimized, meaning sample sizes less than $0.5 \mathrm{mg}$ and pyrolysis temperatures lower than about $260{ }^{\circ} \mathrm{C}$. At higher temperatures, both thermal runaway and interference of the melting endotherm prevent getting accurate thermal histories.

The reaction in an open pan shows evidence for three global processes, although constant heating rate mass loss is described fairly well by a single nucleation-growth model. The activation energies determined by model fitting to multiple thermal histories are similar to those determined by isoconversional analysis.

The decomposition reaction is accelerated in a sealed pan, presumably because gaseous intermediates react with the decomposing solid. The heat release in a closed pan completes $5-10{ }^{\circ} \mathrm{C}$ sooner that either heat release or mass loss in an open pan. A single nucleation-growth model fits the heat release from the sealed pan fairly well, and its use is preferable for cases in which a simple model is needed to predict high explosives performance.

\section{Acknowledgments}

This work was performed under the auspices of the U.S. DOE by UC, Lawrence Livermore National Laboratory under contract number W-7405-Eng-48.

We thank Professor Charles Wight of the University of Utah for supplying us with some of his group's unpublished data for our comparison of methods and Frank Garcia and Kevin Vandersaal for supplying samples.

[1] S. Vyazovkin, C. A. Wight, Ann. Rev. Phys. Chem. 48 (1997) 119.

[2] A. K. Burnham and R. L. Braun, Energy \& Fuels 13 (1999) 1.

[3] Friedman, H. L. J. Polymer Sci., Part C. 6 (1963) 183.

[4] A. K. Burnham, J. Therm. Anal. Cal. 60 (2000) 895.

[5] H. E. Kissinger, Anal. Chem. 29 (1957) 1702. 